\title{
Endocrine gland-derived vascular endothelial growth factor strengthens cell invasion ability via prokineticin receptor 2 in colon cancer cell lines
}

\author{
SHINSUKE TABATA, TAKANORI GOI, TOSHIYUKI NAKAZAWA, YOUHEI KIMURA, \\ KANJI KATAYAMA and AKIO YAMAGUCHI
}

First Department of Surgery, University of Fukui, Yoshida-gun, Fukui, Japan

Received May 14, 2012; Accepted June 13, 2012

DOI: $10.3892 /$ or.2012.2124

\begin{abstract}
Endocrine gland-derived vascular endothelial growth factor (EG-VEGF) has recently been identified as one of the vascular endothelial growth factors, and it is considered that the overexpression of EG-VEGF in colon cancer is related to hepatic metastasis. In this study, we report our recent novel findings of the involvement of EG-VEGF in cell invasion of colon cancer cells. Colon cancer cell lines (DLD-1 and HCT116) with high expression of prokineticin receptor (PK-R) 1 and 2 were stimulated with the EG-VEGF protein. Furthermore, Matrigel cell invasion assay was performed to examine the changes in cancer cell invasion. In addition, we investigated the mRNA expression of matrix metalloproteinase (MMP)-2, -7 and -9 in cancer cells. Finally, the EG-VEGF receptor on the colon cancer cell membrane was blocked by anti-PK-R1 and -PK-R2 antibodies to study whether cell invasion ability would be altered. In colon cancer cell lines where the expression of PK-R1 and 2 was confirmed, stimulation with EG-VEGF increased cell invasion a maximum of 3-5 times. Furthermore, an increase in the mRNA and protein expression of MMP-2, -7 and -9 was observed. We also observed that the cell invasion rate decreased only after exposure to the antiPK-R2 antibody. The study showed that the EG-VEGF protein may act on MMP-2, -7 and -9 via PK-R2 to strengthen cell invasion ability in colon cancer cell lines.
\end{abstract}

\section{Introduction}

At present, a major issue related to treating gastrointestinal cancers is dealing with metastasis, as this may determine

Correspondence to: Dr Takanori Goi, First Department of Surgery, University of Fukui, 23-3 Eiheiji-cho, Yoshida-gun, Fukui, Japan

E-mail: tgoi@u-fukui.ac.jp

Abbrevations: PK-R1, prokineticin receptor 1; PK-R2, prokineticin receptor 2

Key words: invasion, colon cancer, endocrine gland-derived vascular endothelial growth factor patient prognosis. Among the different types of cancer, colon cancer is characterized by susceptibility to hematogenous metastasis, particularly hepatic metastasis. Successful management of hematogenous metastasis is considered vital for an improvement in the survival rate of these patients $(1,2)$.

Colon cancer metastasis occurs possibly through the following mechanism: after detaching from the primary lesion, the cancer cells invade capillary vessels, pass through the portal system and greater circulatory system, spread across the whole body, adhere to vascular endothelial cells of a target organ, transmigrate and invade outside the blood vessels and grow in the metastatic lesion. Cancer cells have been clinically shown to undergo such invasive processes, and those cancer cells that have high invasive ability are considered likely to cause metastasis and poor prognosis (3). The endocrine glandderived vascular endothelial growth factor (EG-VEGF) gene that was investigated in this study was identified by LeCouter et al in 2001 as an angiogenic growth factor for organs of the endocrine system. EG-VEGF consists of 305 amino acids with a molecular weight of $8.6 \mathrm{kDa}$. A mature EG-VEGF protein has 86 amino acids containing 10 cysteines, with $80 \%$ homology to a non-toxic protein purified from the venom of the black mamba snake, whereas homology to the vascular endothelial growth factor (VEGF) is weak (4). Recently, prokineticin receptor (PK-R) 1 and 2 were identified as EG-VEGF receptors and these receptors were shown to mediate physiological changes (5-7).

This study demonstrates our findings of a new mechanism by which signal transmission to matrix metalloproteinase (MMP) via PK-R2 occurs after stimulation with the EG-VEGF protein, thereby accelerating cell invasion in colon cancer cells.

\section{Materials and methods}

Cell culture. The human colon cancer cell lines, DLD-1 and HCT116, were cultured at $37^{\circ} \mathrm{C}$ in $5 \% \mathrm{CO}_{2}$ in RPMI-1640 medium containing $10 \%$ fetal bovine serum (8).

Antibody. The following antibodies were used: anti-human PK-R1 and PK-R2 Ab (Novus Biochemicals, Littleton, CO, USA). 
Immunohistostaining. The cells were plated in 96-well plates at $1 \times 10^{4}$ and incubated for $12 \mathrm{~h}$. The cells were analyzed for protein expression using the streptavidin-biotin peroxidase method $(9,10)$.

Chemicals. EG-VEGF proteins were dissolved in distilled water according to the manufacturer's instructions (Shenandoah Biotechnology, Inc., Warwick, PA, USA).

Antibody treatment. Cancer cells were plated in $10-\mathrm{cm}$ dishes at $5 \times 10^{5}$ and incubated for $12 \mathrm{~h}$. The cells were treated with antibody at $10 \mu \mathrm{g} / \mathrm{ml}$ for $3 \mathrm{~h}$.

Tumor cell invasion assay. Transwells (Biocoat Matrigel 6-well invasion chamber) with filters coated with an extracellular matrix (Matrigel) on the upper surface were purchased from BD Biosciences (San Jose, CA, USA). A complete medium was added to the bottom chamber to induce the invasion of the cells through the Matrigel. A serum-free medium with or without EG-VEGF protein was added to the cells $\left(2 \times 10^{5}\right)$, and seeded to the top chamber. The Matrigel invasion chamber was incubated for $48 \mathrm{~h}$ at $37^{\circ} \mathrm{C}$ with $5 \% \mathrm{CO}_{2}$. Non-invading cells were removed from the top of the Matrigel with a cottontipped swab. The number of invasive cells was determined by counting the stained cells. Cell numbers were counted with a hemocytometer (11).

RNA extraction and RT-PCR analysis. Total RNA was extracted from cells using Isogen (Wako, Osaka, Japan). The single-strand cDNA prepared from $3 \mu \mathrm{g}$ of total RNA using PrimeScript RT reagent kit (Takara, Japan) was used as the template for the polymerase chain reaction (PCR) (12). The primers for PCR to amplify MMP-2 gene-coding regions were as follows: 5' primer MMP-2-AX, 5'-ACCCATTTAC ACCTACACCAAG-3'; 3' primer MMP-2-BX, 5'-GTATACC GCATCAATCTTTTCCG. The primers for PCR to amplify MMP-7 gene-coding regions were as follows: 5' primer MMP-7-AX, 5'-TCTTTGGCCTACCTATAACTGG-3'; 3' primer MMP-7-BX, 5'-CTAGACTGCTACCATCCGTCA-3'. The primers for PCR to amplify MMP-9 gene-coding regions were as follows: 5' primer MMP-9-AX, 5'-TGGGCT ACGTGACCTATGACAT-3'; 3' primer MMP-9-BX, 5'-GCC CAGCCCACCTCCACTCCTC-3'. GAPDH amplification was used as an internal PCR control with 5'-GGGGAGCCA AAAGGGTCATCATCT-3' as the sense primer and 5'-GAC GCCTGCTTCACCACCTTCTTG-3' as the antisense primer. Thirty cycles of denaturation $\left(94^{\circ} \mathrm{C}, 1 \mathrm{~min}\right)$, annealing $\left(50^{\circ} \mathrm{C}\right.$, $1.5 \mathrm{~min})$ and extension $\left(72^{\circ} \mathrm{C}, 2 \mathrm{~min}\right)$ were carried out in a thermal cycler (PTC-100, Programmable Thermal Controller; MJ Research Inc., MA, USA). PCR products (10 $\mu \mathrm{l})$ were resolved by electrophoresis in $1.2 \%$ agarose gel. The sequencing was performed on PCR products showing the bands in RT-PCR analysis. Ethidium bromide staining of the gels identified a band of the MMP-2, -7 and -9 mRNA. To ensure reproducibility, all PCR amplifications were performed in triplicate $(8,12)$.

Statistical considerations. Characteristics of the two treatment arms were compared using the Chi-square test. Values

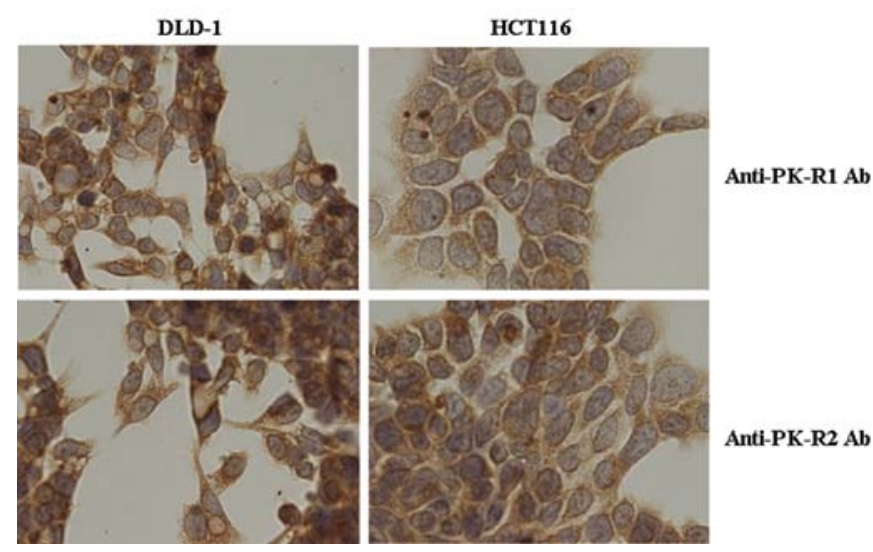

Figure 1. Immunostaining of PK-R1 and PK-R2 isoforms in colon cancer cell lines: DLD-1 and HCT116. Expression of PK-R1 and PK-R2 was expressed in both cancer cell lines.

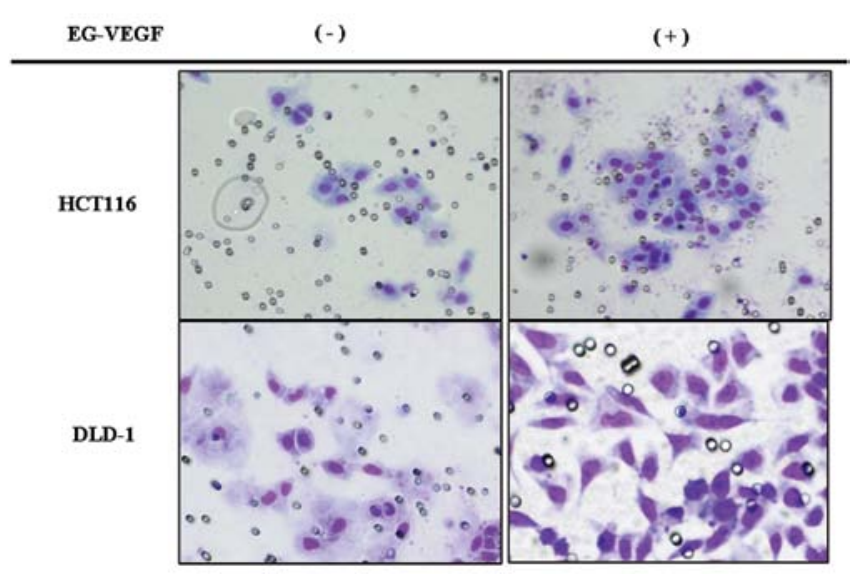

Figure 2. Colon cancer cell invasion. Cells were treated with EG-VEGF protein, and the invasive cells in the lower chamber were stained using Matrigel assay and identified with a microscope.

of $\mathrm{P}<0.05$ were considered to indicate statistically significant results.

\section{Results}

Expression levels of $P K-R 1$ and $P K-R 2$ in colon cancer cells. Fig. 1 shows the stained image of colon cancer cells HCT116 and DLD-1 incubated with anti-PK-R1 and anti-PK-R2 antibodies. The expression levels of PK-R1 and PK-R2 in these cancer cell lines were confirmed.

Invasive ability of the colon cancer cell lines. Figs. 2 and 3 demonstrate the cell invasion after stimulation of colon cancer cells with the EG-VEGF protein. While the number of invasive HCT116 colon cancer cells was 117 on average, the number of invasive HCT116 cells after stimulation with EG-VEGF was 346 on average. Similarly, while the mean number of invasive DLD-1 colon cancer cells was 49 , the mean number of invasive DLD-1 cells following stimulation with EG-VEGF was significantly higher at 288 . 


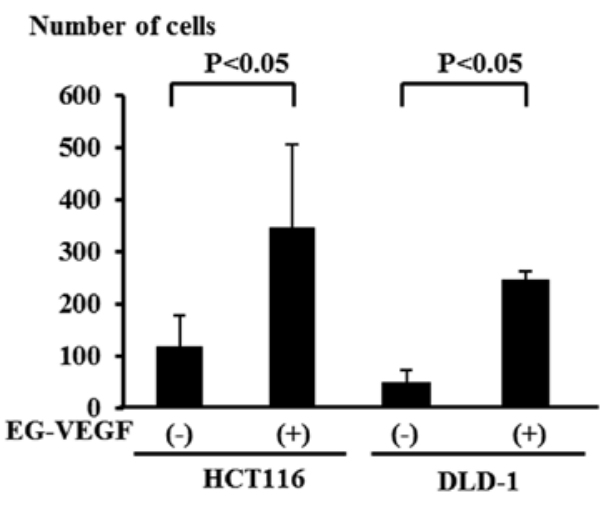

Figure 3. EG-VEGF stimulation induced colon cancer cell invasion. The number of invasive cells was quantitated over $48 \mathrm{~h}$ using Matrigel assay. Results are presented as the means \pm SD.

Expression of MMP-2, -7 and -9 mRNAs in colon cancer cell lines. Results of the expression of MMP-2, -7 and -9 mRNAs in the colon cancer cell lines stimulated with the EG-VEGF protein are shown in Fig. 4. Compared with the cell lines that were not stimulated with EG-VEGF protein, stimulation with EG-VEGF protein increased the expression of MMP-2, -7, and -9 mRNAs in both the HCT116 and DLD-1 cell lines, although the amount of increase was not the same for both cell lines.

Suppression of the invasive ability of colon cancer cell lines by anti-PK-Rl antibody. While 346 HCT116 colon cancer cells were invasive after EG-VEGF stimulation, 316 HCT116 cells were invasive following exposure to the anti-PK-R1 receptor antibody following EG-VEGF stimulation. While 331 DLD-1 cells were invasive following EG-VEGF stimulation, 275 DLD-1 cells were invasive after exposure to the anti-PK-R1 receptor antibody following EG-VEGF stimulation (Fig. 5). Thus, cell invasion was not significantly suppressed.

Suppression of the invasive ability of colon cancer cell lines by anti-PK-R2 antibody. While 346 HCT116 colon cancer cells were invasive after EG-VEGF stimulation, 119 HCT116 cells were invasive following exposure to anti-PK-R2 antibody followed by EG-VEGF stimulation. While 331 DLD-1 cells were invasive following EG-VEGF stimulation, 93 DLD-1 cells were invasive after exposure to the anti-PK-R2 receptor antibody followed by EG-VEGF stimulation (Fig. 5). Thus, cell invasion was significantly suppressed.

\section{Discussion}

The most serious life-threatening condition associated with malignant tumors is metastasis. Possible countermeasures include i) preventing cancer cells from leaving the primary lesion and reaching a target organ; and ii) suppressing the growth of lesions in the metastatic organs. An important phenomenon in the course of metastasis is angiogenesis. Angiogenesis intricately involves the platelet-derived growth factor (PDGF), VEGF and other growth factors as well as their binding status to receptors on an endothelial surface (13-16). Many reports have been published regarding the relationships between these factors and the development of malignant tumors. With the recent advancement of molecular biological techniques, the mechanism of angiogenesis has been elucidated, and various types of angiogenesis inhibitors have shown efficacy in clinical applications (17-22).

EG-VEGF investigated in this study is weakly homologous to and different from VEGF, a known angiogenic factor. According to previous studies, the expression of EG-VEGF in normal human tissue is limited to hormone-producing cells including ovary, testis and placenta, and does not occur in normal gastrointestinal membranes such as the stomach and colon (4). In connection with our investigations on primary lesions in colon cancer, we report the following. The prognosis of patients with positive expression of EG-VEGF mRNA is significantly worse than for patients with negative expression and intensification of EG-VEGF expression is related to angiogenesis and hepatic metastasis $(23,24)$. EG-VEGF expression is also considered highly significant in other malignant tumors and is associated with metastasis of prostate

HCT116

DLD-1

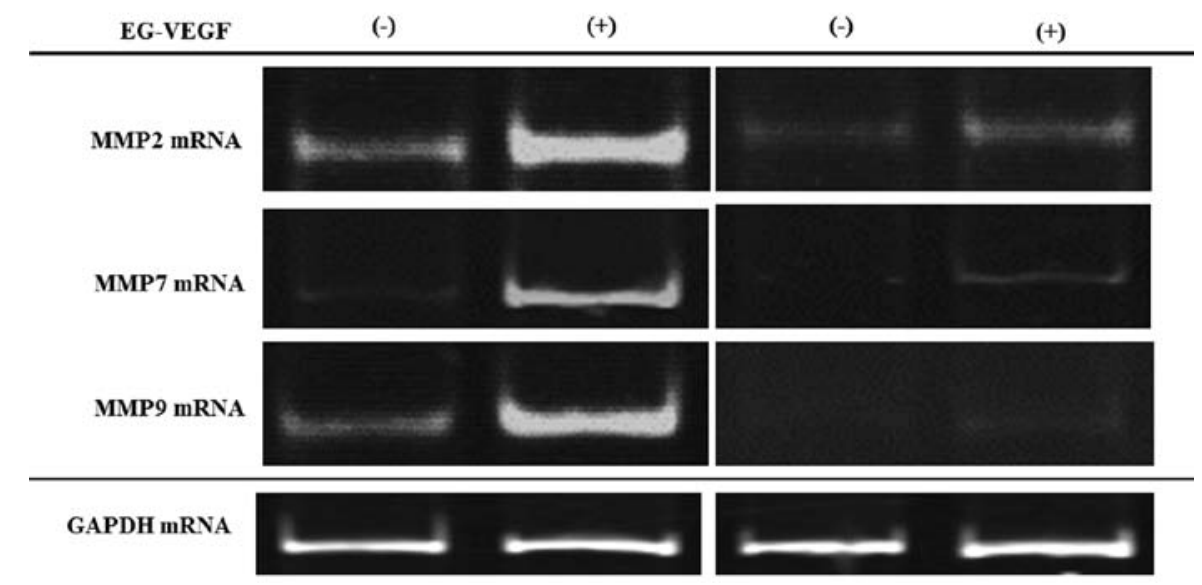

Figure 4. mRNA expression of the MMP family members in EG-VEGF-stimulated colon cancer cell lines. mRNA expression of MMP family members in colon cancer cell lines treated with EG-VEGF was determined by RT-PCR. MMP-2, MMP-7 and MMP-9 mRNA expression levels were increased in EG-VEGF-stimulated colon cancer cell lines in comparison to non-stimulated colon cell lines. 


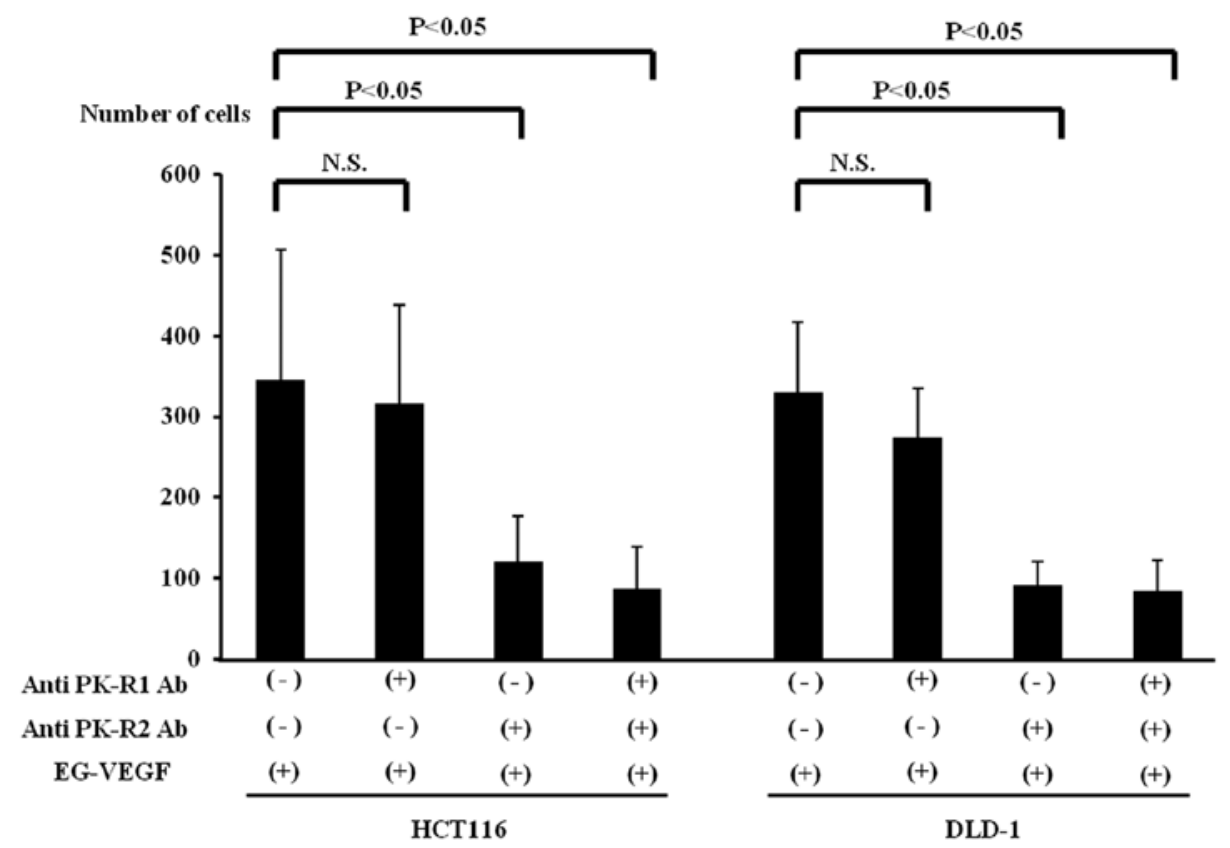

Figure 5. Anti-PK-R2 Ab inhibited the invasion of EG-VEGF-stimulated colon cancer cells. Cells treated with anti-PK-R1 or anti-PK-R2 Ab were stimulated with EG-VEGF and the number of invasive cells was quantitated using Matrigel assay. Results are presented as the means \pm SD. N.S., not significant.

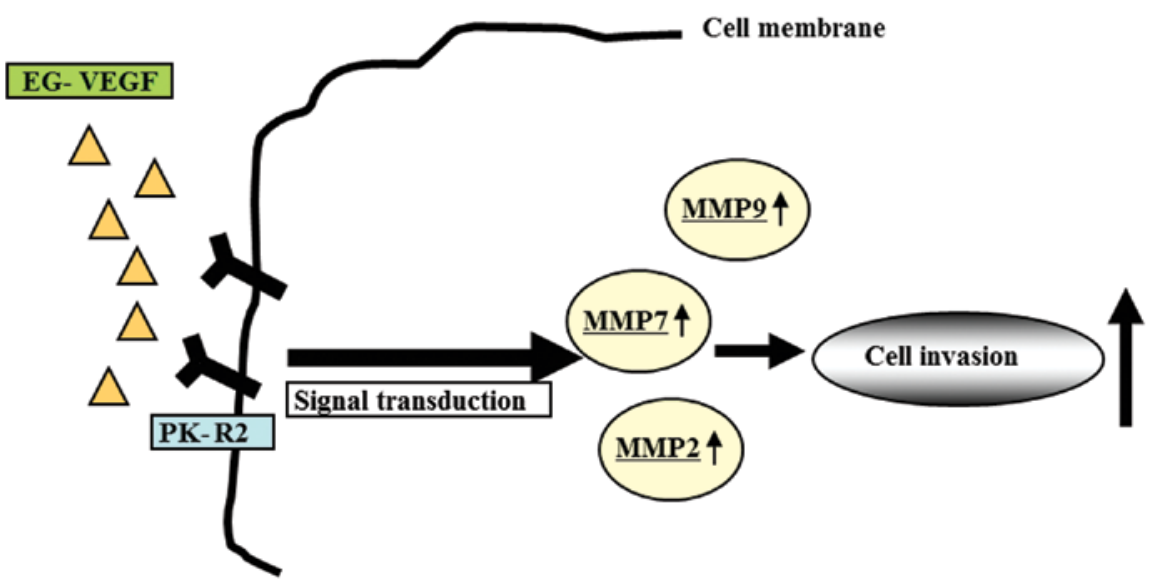

Figure 6. Correlation between EG-VEGF and the cell invasive signaling cascade. EG-VEGF acts on MMP-2, -7 and -9 via PK-R2 to strengthen cell invasion ability in colon cancer cell lines.

cancer/neuroblastoma and the intensification of malignancy in pancreatic duct cancer (25-28). Furthermore, our study showed that EG-VEGF is related to cell invasion ability, which is an indicator of cell malignancy and an important element for the development of hematogenous, lymph node and peritoneal metastasis. The importance of EG-VEGF in malignant cells was thus indicated.

Although not many studies have been conducted on EG-VEGF in colon cancer, regarding the transmission system of EG-VEGF, it is known that information enters the cell via PK-R1 and 2 on the cell membrane, eventually inducing physiological phenomena and other various important events (5-7). To the best of our knowledge, our study showed for the first time that invasive ability of colon cancer cells increases with the stimulation of the EG-VEGF protein and that information of the EG-VEGF protein is possibly transmitted via the PK-R2, which we proved by inhibition of invasion by the anti-PK-R2 antibody. Furthermore, we examined the information transmission system in detail by focusing on the MMP family, which plays an important role in the degradation of the extracellular matrix at the time of migration from the primary lesion to the interstitium and to the inside of vascular channels $(29,30)$. Among the MMP family, MMP-2, -7 , and -9 , are involved in the invasive ability of colon cancer cells $(31,32)$. We examined MMP family members and found that stimulation with the EG-VEGF protein augmented the expression of MMP-2, -7 and -9 genes, suggesting the importance of the MMP family genes.

We showed that the EG-VEGF protein acts on the MMP family genes via the PK-R2 receptor on the cellular membrane, ultimately intensifying the cell invasion ability in colon cancer (Fig. 6). 


\section{References}

1. Muto T, Kotake K and Koyama Y: Colorectal cancer statistics in Japan: data from JSCCR registration, 1974-1993. Int J Clin Oncol 6: 171-176, 2001.

2. Koyama Y and Kotake K: Overview of colorectal cancer in Japan: report from the Registry of the Japanese Society for Cancer of the Colon and Rectum. Dis Colon Rectum 40: 2-9, 1997.

3. Fidler IJ and Ellis LM: The implications of angiogenesis for the biology and therapy of cancer metastasis. Cell 79: 185-188, 1994

4. LeCouter J, Kowalski J, Foster J, Hass P, Zhang Z, DillardTelm L, Frantz G, Rangell L, DeGuzman L, Keller GA, et al: Identification of an angiogenic mitogen selective for endocrine gland endothelium. Nature 412: 877-884, 2001.

5. Soga T, Matsumoto S, Oda T, Saito T, Hijama H, Takasaki J, Kamohara M,Ohishi T, Matsushime $\mathrm{H}$ and Furuichi K: Molecular cloning and characterization of prokineticin receptors. Biochim Biophys Acta 1579: 173-179, 2002.

6. Lin DC, Bullock CM, Eheler FJ, Chen JL, Tian H and Zhou QY: Identification and molecular characterization of two closely related $\mathrm{G}$ protein-coupled receptors activated by prokineticins/ endocrine gland vascular endothelial growth factor. J Biol Chem 277: 19276-19280, 2002.

7. Masuda Y, Takatsu Y, Terao Y, Kumano S, Ishibashi Y, Suenaga M, Abe M, Fukusumi S, Watanabe T, Shintani Y, et al: Isolation and identification of EG-VEGF/prokineticins as cognate ligands for two orphan G-protein-coupled receptors. Biochem Biophys Res Commun 293: 396-402, 2002.

8. Goi T, Yamaguchi A, Nakagawara G, Urano T, Shiku H and Furukawa K: Reduced expression of deleted colorectal carcinoma (DCC) protein in established colon cancers. Br J Cancer 77: 466-471, 1998

9. Yamaguchi A, Urano T, Goi T, Saito M, Takeuchi K, Hirose K, Nakagawara G, Shiku H and Furukawa K: Expression of a CD44 variant containing exons 8 to 10 is a useful independent factor for the prediction of prognosis in colorectal cancer patients. J Clin Oncol 14: 1122-1127, 1996

10. Fujishima Y, Goi T, Kimura Y, Hirono Y, Katayama K and Yamaguchi A: MUC2 protein expression status is useful in assessing the effects of hyperthermic intraperitoneal chemotherapy for peritoneal dissemination of colon cancer. Int J Oncol 40: 960-964, 2012

11. Sawai K, Goi T, Hirono Y, Katayama K and Yamaguchi A: Survivin-3B gene decreases the invasion-inhibitory effect of colon cancer cells with 5-fluorouracil. Oncol Res 18: 541-547, 2010.

12. Goi T, Yamaguchi A, Takeuchi K, Nakagawa G, Yamashiro S, Furukawa K, Urano T and Shiku H: CD44 with variant exons 8-10 in colorectal tumors: expression analysis by a variant exon 9-specific monoclonal antibody. Int J Oncol 8: 657-662, 1996.

13. Ferrara N, Gerber HP and LeCouter J: The biology of VEGF and its receptors. Nat Med 9: 669-676, 2003.

14. Sakurai T and Kudo M: Signaling pathways governing tumor angiogenesis. Oncology 81: 24-29, 2011.

15. Ferrara N and Davis-Smyth T: The biology of vascular endothelial growth factor. Endocr Rev 18: 4-25, 1997.

16. Andrae J, Gallini R and Betsholtz C: Role of platelet-derived growth factors in physiology and medicine. Genes Dev 22: 1276-1312, 2008.

17. Hurwitz H, Fehrenbacher L, Novotny W, Cartwright $T$, Hainsworth J, Heim W, Berlin J, Baron A, Griffing S, Holmgren E et al: Bevacizumab plus irinotecan, fluorouracil, and leucovorin for metastatic colorectal cancer. N Engl J Med 350: 2335-2342, 2004.

18. Giantonio BJ, Catalano PJ, Meropol NJ, O'Dwyer PJ, Mitchell EP, Alberts SR, Schwartz MA and Benson AB III: Bevacizumab in combination with oxaliplatin, fluorouracil, and leucovorin (FOLFOX4) for previously treated metastatic colorectal cancer: results from the Eastern Cooperative Oncology Group Study E3200. J Clin Oncol 25: 1539-1544, 2007.
19. Jonker DJ, O'Callaghan CJ, Karapetis CS, Zalcberg JR, Tu D, Au HJ, Berry SR, Krahn M, Price T, Simes RJ, et al: Cetuximab for the treatment of colorectal cancer. N Engl J Med 357: 2040-2048, 2007.

20. Cunningham D, Humblet Y, Siena S, Khayat D, Bleiberg H, Santoro A, Bets D, Mueser M, Harstrick A, Verslype C, et al: Cetuximab monotherapy and cetuximab plus irinotecan in irinotecan-refractory metastatic colorectal cancer. N Engl J Med 351: 337-345, 2004.

21. Van Cutsem E, Nowacki M, Lang I, Cascinu S, Shchepotin I, Maurel J, Rougier P, Cunningham D, Nippgen J and Kohne C: Randomized phase III study of irinotecan and 5-FU/LV with or without cetuximab in the first line treatment of patients with metastatic colorectal cancer. J Clin Oncol 25: 4000, 2007

22. Van Cutsem E, Peeters M, Siena S, Humblet Y, Hendlisz A, Neyns B, Canon JL, Van Laethem JL, Maurel J, Richardson G, et al: Open-label phase III trial of panitumumab plus best supportive care compared with best supportive care alone in patients with chemotherapy-refractory metastatic colorectal cancer. J Clin Oncol 25: 1658-1664, 2007.

23. Nagano H, Goi T, Koneri K, Hirono Y, Katayama K and Yamaguchi A: Endocrine gland-derived vascular endothelial growth factor (EG-VEGF) expression in colorectal cancer. J Surg Oncol 96: 605-610, 2007.

24. Goi T, Fujioka M, Satoh Y, Tabata S, Koneri K, Nagano H, Hirono Y, Katayama K, Hirose K and Yamaguchi A: Angiogenesis and tumor proliferation/metastasis of human colorectal cancer cell line SW620 transfected with endocrine gland-derivedvascular endothelial growth factor, as a new angiogenic factor. Cancer Res 64: 1906-1910, 2004

25. Ngan ES, Sit FY, Lee K, Miao X, Yuan Z, Wang W, Nicholls JM, Wong KK, Garcia-Barcelo M, Lui VC and Tam PK: Implications of endocrine gland-derived vascular endothelial growth factor/ prokineticin-1 signaling in human neuroblastoma progression. Clin Cancer Res 13: 868-875, 2007.

26. Pasquali D, Rossi V, Staibano S, De Rosa G, Chieffi P, Prezioso D, Mirone V, Mascolo M, Tramontano D, Bellastella A and Sinisi AA: The endocrine-gland-derived vascular endothelial growth factor (EG-VEGF)/prokineticin 1 and 2 and receptor expression in human prostate: up-regulation of EG-VEGF/ prokineticin 1 with malignancy. Endocrinology 147: 4245-4251, 2006.

27. Morales A, Vilchis F, Chávez B, Chan C, Robles-Díaz G and Díaz-Sánchez V: Expression and localization of endocrine gland-derived vascular endothelial growth factor (EG-VEGF) in human pancreas and pancreatic adenocarcinoma. J Steroid Biochem Mol Biol 107: 37-41, 2007.

28. Jiang X, Abiatari I, Kong B, Erkan M, De Oliveira T, Giese NA, Michalski CW, Friess $\mathrm{H}$ and Kleeff J: Pancreatic islet and stellate cells are the main sources of endocrine gland-derived vascular endothelial growth factor/prokineticin-1 in pancreatic cancer. Pancreatology 9: 165-172, 2009.

29. Chakraborti S, Mandal M, Das S, Mandal A and Chakraborti T: Regulation of matrix metalloproteinases: an overview. Mol Cell Biochem 253: 269-285, 2003

30. Rydlova M, Holubec L Jr, Ludvikova M Jr, Kalfert D, Franekova J, Povysil $\mathrm{C}$ and Ludvikova M: Biological activity and clinical implications of the matrix metalloproteinases. Anticancer Res 28: 1389-1397, 2008

31. Zucker S and Vacirca J: Role of matrix metalloproteinases (MMPs) in colorectal cancer. Cancer Metastasis Rev 23: 101-117, 2004.

32. Tomita $\mathrm{T}$ and Iwata $\mathrm{K}$ : Matrix metaIloproteinases and tissue inhibitors of metalloproteinases in colonic adenomas-adenocarcinomas. Dis Colon Rectum 39: 1255-1264, 1996. 